\title{
Optimization of Student Service in College and University Against the Context of Internet Technology
}

\author{
Yongbin $\mathrm{Cao}^{1, *}$ \\ ${ }^{1}$ School of Marxism, Chengdu University, Chengdu, Sichuan 610106, China \\ *Corresponding author.Email: 83990895@qq.com
}

\begin{abstract}
The Internet technology has been mature and widely used, and the new media communication mode has been accepted and sought after by more and more college students on campus. College and university in China are constantly promoting information construction: smart campus supported by new media technology helps to optimize student services. This article studies how to fully utilize the Internet in student service on campus by adopting research and case studies to analyze the role of technology and college students \& apos. And the subjective initiative should be actively brought into play to further optimize campus student services in the way students like best.
\end{abstract}

Keywords: New media, New media technology, Campus student services.

\section{INTRODUCTION}

China's booming economy and its constant emphasis on education have prompted local governments to increase their investment in education year by year, which has historically reached $4 \%$ of GDP. However, despite the huge progress, it is still far behind that of many developed countries. The Chinese economy is in a crucial period of replacing old drivers with new ones and transforming and upgrading its economy. It is shifting from overreliance on natural resources to one driven by human resources and innovation. Education spending should be increased steadily, as evidences from education's service to economic growth, improvement of income distribution (through private income from education and as a direct means of transfer payments) and social governance, horizontal international comparisons, and the need for the education system's reform and development.

China's education investment is dominated by government finance, including pre-school education, primary education, secondary education, higher education and other forms of education finance. Preschool education finance refers to the government investment in preschool children's education, which includes the expenditure on the construction of places and facilities of early childhood education, and the expenditure on the management and administration of early childhood education. In order to guarantee the equality of educational opportunity and the quality of educational output, and promote the further development of the popularization of higher education, the educational funds will inevitably increase. But at the same time, educational resources are always scarce relative to educational needs. There will be such a contradiction. On the one hand, education funds will always be in short supply; On the other hand, the quality of education must not be degraded. Therefore, it is of special significance to increase education finance and improve its utilization efficiency.

China's economic and social and cultural quality draws government and society's attention to education. The rapid development of Internet economy makes it urgent to strengthen the information reform on campus. The information age brings great impact to the campus construction of traditional colleges and universities. Cloud computing, big data, block chain and other technologies have become an indispensable part of the construction of smart campus, and also key supporting facilities for the construction of universities inside and outside China. The influence 
and reform of higher education in the information age on colleges and universities have attracted the attention of all walks of life. The transformation of human society brought about by the information revolution will be an important aspect of education: Whether information construction can bring more equal educational opportunities to underdeveloped areas and vulnerable groups, how do teachers deal with the relationship between teaching and learning in today's highly developed Internet, and the relationship between systematic education and mass education, academic education and lifelong learning in higher education institutions.

College informatization aims to improve the quality of education. The educational idea, educational mode, management mode and technology application under the new form will be the key point of the informatization construction of colleges and universities. This paper discusses the optimization measures of campus student service from the perspective of college student service under the condition of Internet technology, and further considers the development trend of Internet technology in the campus.

In recent years, the optimization and improvement of campus student services is the focus of the campus construction of colleges and universities, and the Internet is increasingly integrated into the study, life and other aspects of the campus. However, the campus student service construction is faced with a series of problems: the low utilization of resources, the information communication platform between the school, teachers and students, and the communication bridge with the outside world is too simple and aging, high cost of student life and learning, and low efficiency of administration. Therefore, the Internet new media technology should be used to optimize the campus student service, provide a more centralized and convenient service platform for teachers and students, and improve the efficiency of transaction processing.

\section{USING THE INTERNET PLATFORM}

More and more college students are pursuing the new ways of media communication. In terms of emerging media, the Internet has become the most important and the most recognized medium among college students. A statistical report on China's Internet development shows that in the first half of 2020, the number of Internet users on mobile terminals in China reached 932 million. These data show that college students receive new media the fastest, use it the most and give timely feedback.

Therefore, campus information construction should cover the whole link of campus life teaching, management, scientific research and service. All business applications should be incorporated into a unified information management system platform, and all business processes should be scientifically classified and managed. All business departments interact with each other, put forward demands and sort out business processes respectively, and create a good campus operating environment, so that teachers and students can participate in various campus activities under the conditions of fast and comfortable Internet platform, which fully reflects the highquality experience of Internet technology platform. At the same time, it can also be further upgraded to provide personalized services for different target groups and develop different teaching plans or growth plans to meet the needs of students' growth under the modern education concept.

All kinds of network terminals are used to connect with each other all the time, and consultation services are provided to student groups to collect needed services as well as their suggestions and opinions. In addition, the collected information is fed back to the service providers to make them continuously improve and complete, so as to enable them to better carry out corresponding services and achieve satisfactory results for all parties.

As for the construction of college campus student service optimization, many colleges and universities have tried "one-stop service center". The ways of linkage of various departments, port embedding and information sharing are used to build the Internet service platform to solve the problems such as time conflict and excessive procedures. "Internet + " can also be employed to build a student affairs service system, optimize procedures, improve efficiency, and provide a platform for the majority of students. The center's main business is information service and centralized processing, adopting the combination of online and offline mode, which breaks the traditional management thinking pattern. Combined with the needs and development of students, the campus public service ecology that deeply integrates intelligent connection, intelligent platform and intelligent application can be built to bring more intelligent services and experience to students.

The construction of campus information needs to pay attention to the following points in the construction of the Internet platform: the functional design of the intelligent service and operation and 
maintenance platform should integrate all the campus functional blocks into a system platform, and ensure the operating efficiency in terms of hardware facilities; all functional subsystems should be integrated into visual management to ensure the stability and sustainability of operation; management efficiency should be guaranteed to prevent all kinds of emergencies beforehand; and the backup system should be set up to ensure data security and application stability, and ultimately achieve service upgrade, process simplification, efficiency improvement, information security. All of these can provide an intelligent sensing living environment and a predictable management model for campus life, giving full play to the effects of development in the Internet age.

\section{GIVING PLAY TO THE CREATIVITY OF COLLEGE STUDENTS}

In view of the fact that on-campus services mostly rely on on-campus official channels, and off-campus service promotion can only rely on various community organizations, community organizations serve as an important part of campus life. Benefiting from students' efficient and rapid acceptance of new things, various activities organized by college associations are effective means to promote and publicize campus services.

In addition, "mass entrepreneurship and innovation" make college students, who are already full of hope for the future, the most likely group to create miracles on the Internet platform. A series of measures, such as tax relief, loan subsidies and entrepreneurship assistance, have been introduced to encourage college students to innovate and start their own businesses, develop new technologies, new products, new business forms and new models, and create new engines of development, which gives full play to the ability and potential of college students to start businesses and innovate on the Internet, stimulates new economic growth points and forms new drivers.

Internet platforms with disruptive promotion speed and smooth information channels can quickly accumulate customer resources, lowering start-up cost. This is especially true for students majoring in art, as it can boost the cultural and creative industry. According to an official survey, 50 percent of students majoring in art are confident about starting a business, believing that they will have a bright future in art design, photography, advertising and other fields through Internet platforms. In addition, students majoring in art have unique advantages in starting businesses in the field of cultural and creative industries. They can combine their creative ideas with market demands quickly, and even design and manufacture their own creative products Compared with entrepreneurs in other majors or industries who need a lot of capital, venues, equipment and other resources, students majoring in art who start a business in the cultural and creative industry with the help of the Internet need less capital and equipment at the initial stage, with lower costs and relatively easy management. For example, they can set up a photography studio with only computers, printers, cameras and other equipment.

College students, as a highly educated group in society, have the ability to adapt and learn quickly, and can give full play to their creative ability to upgrade and transform the application of relevant technologies according to the needs of their own or target groups. They can develop mobile APP or WeChat small program, which is also the object that should be paid attention to in the current campus student service optimization process.

\section{4. "SPEAKING" IN THE WAY STUDENTS LIKE}

As for the promotion of campus services, the mature Internet technology platform can also adopt the emerging promotion methods. More indirect activities, especially public welfare activities, can be employed at the initial stage of promotion to reduce the resistance of college students.

Non-commercial publicity activities can be carried out to attract students to participate in the campus, so that they can feel the campus services and become more satisfied with campus life. What's more, the student team can participate in the process of platform construction or later operation and maintenance, so that they can enjoy dividends brought by the Internet platform and reach the resonance of campus services under the Internet new media technology.

"Fashionistas" can be adopted to direct campus services and reduce resistance, which is more efficient and faster than celebrity endorsement.

Such promotion can be applied to many fields, including on-campus free platform promotion and off-campus commercial promotion, so that the business promotion model can better fit the campus culture and the needs of students. In this way, the disadvantages inherent in the traditional business model, such as low efficiency, wide coverage, high 
cost and low benefit, can be avoided. Relevant entrepreneurial teams on campus can also be encouraged to form a good brand promotion effect and brand influence.

\section{CONCLUSION}

Based on the trend of campus student service optimization, Internet new media technology are integrated in this paper to adapt to the mainstream of social development, pool resources, integrate the platform, and provide convenience for students in campus life and study. At the same time, the frontier of technological development can be seized, and students' innovation consciousness can be stimulated, making them the leaders of innovation and entrepreneurship. In addition, this paper provides a reference for the campus student service optimization of other colleges and universities.

\section{AUTHORS' CONTRIBUTIONS}

This paper is independently completed by Yongbin Cao.

\section{REFERENCES}

[1] Sun Cuigai, Ao Jianhua. Research on the Construction of College Wechat Integrated Information Service Platform under the Framework of Intelligent Campus [J]. Software Engineering. No. 3, 2020. (in Chinese)

[2] Yang Qicheng, Huang Yin. Research on the Construction of Digital Campus Information Service Platform Based on the SOA and Cloud Computing Technology [J]. Journal of $\mathrm{Xi}^{\text {'an }}$ University of Arts \& Science: Natural Science Edition. 2017(01): 34-38. (in Chinese)

[3] Yu Changhong. Research on the Construction of Intelligence Service and Maintenance Platform of Smart Campus [J]. CET China Educational Technology, Issue 8, 2015. (in Chinese)

[4] Jiang Ying. Research on the construction of smart campus smart service platform [J]. Electronic Technology \& Software Engineering, 2016 (24): 191-192. (in Chinese)

[5] Chen Keming. Research on the Construction of University Campus service Platform in University in the era of big Data [J]. Digital Technology and Application, 2015 (12): 95. (in Chinese)
[6] Su Juan, Zhou Na. Development and operation of the WeChat platform for intelligent integrated services in universities [J]. Science and Technology Innovation and Application, 2018 (12): 44-45. (in Chinese)

[7] Huang Haobo, He Weihua. The WeChat public service platform was officially opened and operated [J]. Journal of Qingdao Technological University, 2019 (01): 47-51. (in Chinese) 